\title{
Research on Reform of Comprehensive Administrative Law Enforcement in Xinjiang Uygur Autonomous Region——Take Aksu Prefecture as an example
}

\author{
Zhang Ting, Ma Zhaowei, Zhang Chuanhui \\ College of Economic and Management, Tarim University, Alar, Xinjiang 843300
}

Keywords: Xinjiang, comprehensive administrative law enforcement, reform

\begin{abstract}
Promoting comprehensive administrative law enforcement is an important task of the reform of the administrative law enforcement system, and also the objective requirement of building a responsibility system and an organizational system for the modern government. Compared with other provinces, the implementation of the policy of comprehensive administrative law enforcement started relatively late in Xinjiang, and there are still many problems in the reform of comprehensive administrative law enforcement, such as undefined legal status of the subject of law enforcement, disunity in legislative basis, non-standardized enforcement procedure, complex relationship in transfer of functions and powers, insufficient coordination between departments, inactive law enforcement force at the grass-roots level and disunity in the establishment of the law enforcement team, which are detrimental to the implementation of comprehensive administrative law enforcement. Therefore, this paper mainly studies the reform of comprehensive administrative law enforcement in Aksu Prefecture, Xinjiang, hoping to promote the deepening of the reform of comprehensive administrative law enforcement in Xinjiang Uygur Autonomous Region.
\end{abstract}

\section{Introduction}

As the government pays increasing attention to the reform of the administrative law enforcement system, the implementation of comprehensive administrative law enforcement has been the focus and difficulty of provincial governments. The reform of comprehensive administrative law enforcement is involved in the reform of Super-Ministry System in urban administrative and law enforcement, straightening out the management system and clarifying the rights and liabilities, shifting down the focus of law enforcement and coordinating the resolution of the nature of the institution and the establishment of law enforcement officers. In the context of overall planning to promote urban and rural integration, administrative law enforcement is an important link for the policy of streamlining government and delegating authorities to cancel or decentralize a large number of administrative approval matters, enhance the regulatory capacity of local governments and strengthen the supervision in and after the event. In the overall governance mode, promoting the reform and innovation of comprehensive administrative law enforcement is to integrate resources of administrative law enforcement and relatively centralize authorities of administrative law enforcement, promote the focus of administrative law enforcement to shift down, and achieve the transformation of administrative law enforcement system in structural reorganization, aggregation of functions, information sharing, process optimization, business collaboration and rule-of-law operation. The reform of comprehensive administrative law enforcement not only includes the optimization of the administrative power allocation and scientific adjustment of organizational establishment, but also includes combing of the responsibility relationships between the government departments concerned and the reconstruction of the law enforcement mechanism and enforcement process, the essence of which is to establish the authoritative and efficient administrative law enforcement system with integration of power and responsibility through the optimization of the government responsibility system and the organization system and the reconstruction of administrative law enforcement system. 


\section{Practical significance of promoting the reform of comprehensive administrative law enforcement in Aksu Prefecture}

Promoting comprehensive administrative law enforcement is the objective requirement of building a responsibility system and an organizational system for the modern government. In the new situation of deepening the all-round reform, promoting the modernization of government governance has become the basic goal of the government's reform, the core of which is to build the government's responsibility system and organizational system according to law, define the boundaries of government functions, optimize the allocation of power and organizational structure, and improve the effectiveness of governance. In terms of connotation, the comprehensive administrative law enforcement is not only to relatively centralize the authority of administrative penalties, but also to further integrate the related administrative supervision and inspection, administrative arbitrariness and other functions. On the other hand, comprehensive administrative law enforcement not only refers to the centralization and integration of authority of administrative penalties and other authorities, but also includes combing of responsibility relationships of relevant government departments, optimization of law enforcement mechanism, reconstruction of law enforcement process, law enforcement norms and management of law enforcement team. Comprehensive administrative law enforcement involves both the reconstruction of the government's responsibility system and the optimization of the organizational system of the government, which is an objective requirement to promote the modernization of government governance. And promoting the comprehensive administrative law enforcement is an important way to transform government functions. Administrative law enforcement system is an important part of the administrative system, and the core of its reform is to optimize the allocation of functions, change government functions, and improve administrative execution and credibility. We should promote streamlining government and delegating authorities, deepen the reform of the administrative approval system and transfer the focus from prior approval to supervision in and after the matter. Meanwhile, an important link in such transformation is to promote the comprehensive administrative law enforcement, change the status of government law enforcement in scattered functional configuration, weak power, poor cooperativity and low efficiency, optimize the function and power allocation of administrative law enforcement in an all-round way and realize cohesion, orderly and coordinated promotion of "Put it down, hold it, manage it well" and effectively change the government's regulatory concepts, systems, mechanisms and methods.

\section{Analysis of problems in the reform of comprehensive administrative law enforcement in Aksu Prefecture}

First, the subject of the comprehensive administrative law enforcement is the national power in administrative law enforcement and the institution of comprehensive administrative law enforcement with the quasi judicial nature, but there are no corresponding administrative regulations to legalize its subject qualification and its legal status is vague, so that it is difficult to guarantee the smooth implementation of the comprehensive administrative law enforcement. Second, it is insufficient in the legal basis and procedure standardization of comprehensive administrative law enforcement and the deterrence of illegal disposal. Due to historical reasons, the basis for the administrative law enforcement in the local governments of Aksu is mostly a great variety of departmental rules and other normative documents. In the process of the implementation of comprehensive administrative law enforcement, due to the defects in the connection between laws, regulations and normative documents, there is confusion and even conflicts when the law enforcement is applied, which directly affects the impartiality, efficiency and authority of the comprehensive law enforcement.

With the development and operation of the comprehensive law enforcement, some problems and contradictions have appeared in the actual reform. In particular, the institutional problems, such as the relationship between the comprehensive law enforcement agencies and the functional departments, have not yet been straightened out, affecting the effectiveness of the comprehensive 
law enforcement. On the one hand, the standard of transfer of functions and powers is not scientific enough. There is no unified definition standard for the transfer of functions, and the basis for transfer is different. On the other hand, the technical support of law enforcement is inadequate. Although some areas have taken comprehensive administrative law enforcement, but the technical supporting forces of the relevant departments have not been transferred, and the inspection force is still insufficient. All of these have greatly limited the smooth development of the comprehensive administrative law enforcement.

In recent years, with the promotion of the transformation in the government functions and streamlining government and delegating authorities, many matters concerned about administrative law enforcement are transferred to the grass-roots departments to bear, and then responsibilities of administrative law enforcement departments have increased significantly. However, the grass-roots departments have seriously inadequate law enforcement force, and there is a wide range of the law enforcement objects, involving a large number of laws and regulations, which also has a higher requirement for the comprehensive quality and professional proficiency of law enforcement personnel. The law enforcement team is not unified. At present, there are various law enforcement agencies in different natures, including administrative organizations, public utilities and public institutions, while the personnel is numerous and jumbled, including administrative workers, and public utilities, as well as supernumerary employees. In the integration and transfer of the law enforcement team, the personnel in different natures is brought into the comprehensive law enforcement team, and the personnel transfer lacks clear classification standard and basis, resulting in various identities of the personnel and the disunity of treatment standards, which will not be conducive to managing law-based administration and law enforcement team, as well as mobilizing the enthusiasm of law enforcement personnel.

\section{Countermeasures to break difficulties in the reform of comprehensive administrative law enforcement}

In accordance with the deployment requirements to comprehensively promote the rule of law and establish the law-based government, we should further establish and perfect the legal system of comprehensive administrative law enforcement and form a scientific and rational system of administrative law enforcement. First, we should conduct unified and corresponding modifications on the existing applicable laws about comprehensive administrative law enforcement, strengthen the cleaning of the laws and regulations and normative documents in effect about administrative law enforcement, and try to eliminate the conflicts in legal norms and develop the unified "Law of Comprehensive Administrative Law Enforcement". Second, we should improve the rules and regulations of administrative law enforcement, including regulations for handling cases, accountability for management by objective of administrative law enforcement, routine inspection, case trial, reporting and complaint handling for the violations by law enforcement officers, thorough investigation on administrative law enforcement, performance appraisal methods of administrative law enforcement, accountability for misjudged case and other important systems, so as to give priority to standardized and practical systems, take the system to handle matters and restrict the people and implement law-based administration. Third, it is to standardize the investigation and taking of evidence, which is an important part of the law enforcement agencies to deal with the case. It is not only the premise to ascertain the facts and correctly apply the law, but is also directly related to the eventual legal effect of specific administrative act, such as administrative handling and administrative penalty. What's more, it is facing the legal risks of administrative reconsideration and failure in administrative proceedings. In practice, for different employers, different complainants and even different law enforcement officers, investigation methods are not the same, but generally speaking, the investigation should follow certain principles and procedures, take certain measures and methods, but also need to apply certain skills.

The purpose of the reform of comprehensive administrative law enforcement is to integrate law enforcement resources, achieve trans-department and interdisciplinary comprehensive law enforcement, and break the absence of law enforcement subjects and weak grass-roots forces. We 
may take the object and efficiency of law enforcement as the core to integrate the law enforcement agencies in similar fields, significantly reduce the number of law enforcement teams, strive for a team to enforce the law to the end, and break the problems in duplicate law enforcement, repeated enforcement and cross enforcement, reduce the number of law enforcement teams, and gradually develop to "wide functions but few institutions" to strengthen the supervision efforts. The structural reorganization of comprehensive administrative law enforcement should be conducted in sections step by step to gradually promote the orderly reorganization according to three categories of comprehensive law enforcement within the department, trans-department and trans-sectoral comprehensive law enforcement and regional comprehensive law enforcement, and then plan and integrate resources of administrative law enforcement from easy to difficult. The reform of comprehensive administrative law enforcement should also strengthen the organic convergence and interaction with the supervision of professional departments, improve the seamless docking in the supervision chain and ultimately form the governance structure of the grass-roots governments in "centralized approval--classified supervision and service optimization-- comprehensive law enforcement”.

We should improve the dependency management system of the comprehensive administrative law enforcement, strengthen the supervision capacity of grassroots governments, and complete abolishing and merging of institutions and establishment transfer according to the principle that "The establishment goes with the personnel and the personnel goes with the matters" and "Streamlining the organizations and strengthening the grass-roots", streamline and merge the original law enforcement team of the department, and incline the establishment resources properly to the grass-roots departments as the focus of law enforcement shifts down, and accordingly transfer the establishment of relevant departments and law enforcement personnel, optimize staffing configuration, and set the focus on strengthening the establishment of grass-roots law enforcement agencies. Moreover, we should set up the independent position sequence for the public servants of administrative law enforcement, implement the position classification and the appointment system, open up the promotion channels for law enforcement officers and construct a more professional, efficient and honest law enforcement team. The change of personnel identity is strictly in accordance with the civil servant law and relevant regulations. Qingdao city has made the beneficial exploration in the innovative personnel management system of administrative law enforcement, and broken the original boundaries of institutional identity, and conducted post management according to the principle of "identity storage, full employment, performance appraisal, post salary". Meanwhile, it has also established the allowance system for special posts of law enforcement officers, appropriately increased the treatment of comprehensive administrative law enforcement personnel and stabilized the law enforcement team.

The relations between professional law enforcement and comprehensive law enforcement should be handled in accordance with the principle of territory, and the matters of higher and lower administrative organizations in equal law enforcement functions should be shifted down to county governments without exception. Duty transfer should highlight the problem direction and demand direction according to laws and regulations. For example, provisions for comprehensive administrative law enforcement are laws and regulations in environmental sanitation, urban and rural planning, municipal utilities and other aspects, as well as the related powers of administrative supervision and inspection, and administrative arbitrariness, so as to strengthen the market supervision responsibilities of local governments and realize the physical concentration of integration of law enforcement agencies and the chemical fusion of the recombination of law enforcement functions. The specialization and integration of administrative law enforcement complement each other. It should conduct internal integration and professional law enforcement in the fields of high specialization and the fields that should be focused on, such as environmental governance, financial supervision, public security and fire protection. The focus of the fields in trans-department comprehensive law enforcement should be the fields in public security, urban management, and social governance in the grass-roots with high frequency of problems, close relationship with the people's daily production and lives, prominent problems in duplicate, repeated 
and cross law enforcement and proper requirements for professional technology.

\section{Acknowledgments}

National Social and Science Fund: : Study on the legal guarantee mechanism of long-term stability in Xinjiang ( Project No.14BFX040)

\section{References}

[1] Qian Ningfeng. Discussion on Reform of Comprehensive Administrative Law Enforcement [J]. The Masses, 2015(07): 57-58.

[2] Xia Defeng. Difficulties and Solutions to Reform of Comprehensive Administrative Law Enforcement [J]. Chinese Public Administration, 2016 (06): 56-56.

[3] Liu Qing. Ways to Promote Reform of Comprehensive Administrative Law Enforcement System [J]. Research of Administrative Science, 2017 (03): 33-33.

[4] Zhang Lixue, Ren Fangfang. Exploration into Reform Path of Comprehensive Administrative Law Enforcement System [J]. Research of Administrative Science, 2016 (04): 36-36. 